University of Nebraska - Lincoln

DigitalCommons@University of Nebraska - Lincoln

Perceptions of Communication With Gay and Lesbian Family Members: Predictors of Relational Satisfaction and Implications for Outgroup Attitudes

Jordan Soliz

University of Nebraska-Lincoln, jsoliz2@unl.edu

Elizabeth Ribarsky

University of Illinois at Springfield, eriba2@uis.edu

Meredith Marko Harrigan

STATE UNIVERSITY OF NEW YORK-Geneseo, harrigan@geneseo.edu

Stacy Tye-Williams

lowa State University, styewill@iastate.edu

Follow this and additional works at: https://digitalcommons.unl.edu/commstudiespapers

Part of the Gender, Race, Sexuality, and Ethnicity in Communication Commons, and the Interpersonal and Small Group Communication Commons

Soliz, Jordan; Ribarsky, Elizabeth; Harrigan, Meredith Marko; and Tye-Williams, Stacy, "Perceptions of Communication With Gay and Lesbian Family Members: Predictors of Relational Satisfaction and Implications for Outgroup Attitudes" (2010). Papers in Communication Studies. 35.

https://digitalcommons.unl.edu/commstudiespapers/35

This Article is brought to you for free and open access by the Communication Studies, Department of at DigitalCommons@University of Nebraska - Lincoln. It has been accepted for inclusion in Papers in Communication Studies by an authorized administrator of DigitalCommons@University of Nebraska - Lincoln. 


\title{
Perceptions of Communication With Gay and Lesbian Family Members: Predictors of Relational Satisfaction and Implications for Outgroup Attitudes
}

\author{
Jordan Soliz, Elizabeth Ribarsky, \\ Meredith Marko Harrigan, and Stacy Tye-Williams
}

\begin{abstract}
This study investigates perceptions of family communication among members with different sexual identities. Specifically, from the perspective of heterosexual family members $(N=129)$, the study takes an intergroup perspective to determine how accommodative and non-accommodative communication and attitudes toward homosexuality predict intergroup anxiety and relational satisfaction with gay or lesbian family members. Further, the manner in which family communication influences attitudes toward homosexuality is examined. Results are discussed in terms of implications for research on heterosexual-homosexual interaction, family communication, and intergroup communication, in general.
\end{abstract}

Keywords: Communication Accommodation; Intergroup Communication; Outgroup Attitudes; Relational Satisfaction; Sexual Identity

Jordan Soliz (Ph.D., University of Kansas, 2004) is an assistant professor in the Department of Communication Studies at the University of Nebraska-Lincoln. Elizabeth Ribarsky (M.A., Central Michigan University, 2004) is an assistant professor in the Department of Communication at the University of Illinois-Springfield. Meredith Marko Harrigan (Ph.D., University of Nebraska-Lincoln, 2006) is an assistant professor in the Communication Department at the State University of New York-Geneseo. Stacy Tye-Williams (M.A., University of Wisconsin- Milwaukee, 2003) is a lecturer at Creighton University. Corresponding author - Jordan Soliz, Department of Communication Studies, University of NebraskaLincoln, Lincoln, NE 68588-0329; email jsoliz2@unl.edu 
Although many individuals and organizations have attempted to make strides in promoting acceptance of gay men and lesbians, there is a continued prevalence of negative attitudes toward homosexuality (Day \& Schoenrade, 1997; Herek, 1994). This intolerance has left many gay men and lesbians feeling socially isolated (Seidman, Meeks, \& Traschen, 1999), even among their own families, which is one of the most important sources of social interaction and support (Robbins et al., 2003). In an attempt to understand the dynamics of interaction between individuals with different sexual identities, most of the research has focused on contact between strangers or friends (e.g., Herek \& Capitanio, 1996), which, although significant, does not address the fact that the family is a context in which relationships exist between individuals with divergent sexual identities. Recognizing that many families consist of gay or lesbian family members and given the increased recognition of "families as critical contexts for communication research" (Turner \& West, 2003, p. 182), a majority of family communication scholars in this context have focused on understanding communication practices associated with creating, managing, and legitimizing family identity in gay- and lesbian-headed families (Bergen, Suter, \& Daas, 2006; Galvin, 2006; Suter, Daas, \& Bergen, 2008; West \& Turner, 1995), children's disclosure and parental responses, and relational maintenance in gay and lesbian couples (Peplau \& Beals, 2004).

Rather than focusing on gay- and lesbian-headed families or the process of sexual identity disclosure, this study investigates communication between family members with different sexual identities to enhance our understanding of the communication processes associated with harmonious relationships in this family type. Because societal views (e.g., attitudes toward homosexuality) pervade family functioning (Harwood, Soliz, \& Lin, 2006), potential challenges exist in these families as divergent sexual identities create a context in which family communication and relationships may be negatively influenced by the intergroup dynamics associated with different social identities. Specifically, the aims of the study are to (a) understand the relationship among attitudes toward homosexuality, family communicative dynamics, relational satisfaction, and intergroup anxiety; and (b) determine how perceptions of family communication may be associated with attitudes toward homosexuals and homosexuality, in general.

A majority of the research on families with a gay or lesbian family member has focused on the challenges and negative aspects of the relationships. For example, societal views of homosexuality influence expectations of parenting and, therefore, parents may be unsure of how to "parent" a gay or lesbian child (LaSala, 2000), creating significant anxiety. Moreover, many parents are in shock and feel like failures when they discover their child's sexual identity (Ben-Ari, 1995; Saltzburg, 2004) and may question if something they did (or did not do) influenced this identity. Although many family members have a difficult time adjusting to having a gay or lesbian family member, fathers, in particular, often have trouble adjusting their "real man" perspectives to fit their son's sexual identity (Floyd, 2001). Similarly, parents often suf- 
fer cognitive dissonance when trying to understand the conflict between inundation of negative images surrounding homosexuality and the loving relationship they have established with their child (Boxer, Cook, \& Herdt, 1991). Although the child is the same person, a new dimension is added to the relationship after a child's sexual identity has been disclosed (Mosher, 2001). This new dimension may increase uncertainty, causing family members to reassess their relationship with their gay or lesbian family member. In a study of gay and lesbian youth who had disclosed sexual identity to their parents, approximately one half of mothers and siblings were understanding, and less than one fourth of the fathers were accepting (D'Augelli, Hershberger, \& Pilkington, 1998). Hence, this uneasiness and lack of acceptance can put a significant strain on the relationship among family members.

Many gay men and lesbians avoid revealing their sexual identity because they fear rejection or strain on their interactions (Mays, Chatters, Cochran, \& Mackness, 1998; Merighi \& Grimes, 2000; Morrow, 2004; Oswald, 2002a, 2002b) and are concerned that stereotypes surrounding sexual identity will change their established relationships. Not disclosing one's sexual identity may lead to avoiding interactions overall, even with family members. This avoidance is particularly troubling considering family is one of the greatest sources of social support and interaction (Robbins et al., 2003). Unfortunately, such a breakdown in family relationships is linked to a greater risk of social isolation, depression, and suicide (Kourany, 1987).

Although this research paints a bleak picture of family relationships characterized by divergent sexual identities, these relationships are obviously not fated to be negative. Some family members may possess ambivalent or positive attitudes toward homosexuality and, therefore, the challenges may not be present. On the other hand, where more negative attitudes do exist, the nature of the communication between family members may overcome barriers and, possibly, ameliorate negative attitudes toward homosexuality overall. Understanding the communicative dynamics in this relationship is an important avenue for research.

Few researchers have examined communication with gay or lesbian family members. However, Oswald (2002a) found that individuals can help construct more supportive interactions with family members. First, intentionality involves conscious actions by the family to validate the individual as a member of the family, such as continuing to involve him or her in family activities. Second, support may be constructed through redefinition, where the family system will adapt to affirm one's identity, such as openly discussing sexual identity. By engaging in open and confirming interactions with gay men or lesbian family members, family members can create a supportive environment.

In sum, the challenges in these families are representative of an intergroup influence on attitudes and interactions. In this context, the family dynamics and relationships may be influenced by the different social identities - specifically, sexual identities - of the family members. Hence, based on this intergroup perspective, this study focuses on heterosexual family members' perceptions of family dynamics. 


\section{Intergroup Perspective on Families}

Recently, scholars have focused on and called for more attention to the role of intergroup processes in understanding interactions and relationships (Harwood, 2006; Harwood \& Giles, 2005). As Harwood (2006) stated, “We need to understand collective identities as a key aspect of human behavior, and we need to think about incorporating this higher-level sense of self into our communication research as a more routine issue" (p. 89). Although intergroup contact has traditionally been thought of solely as contact between strangers, recent research has demonstrated how social categorization and identities can pervade our personal relationships. For example, research on interracial friendships (Diggs \& Clark, 2002) and romantic relationships (Gaines et al., 1999; Troy, Lewis-Smith, \& Laurenceau, 2006) demonstrates that individuals must manage divergent social identities in their relationship. Likewise, scholars have examined cross-group friendships (Paolini, Hewstone, Cairns, \& Voci, 2004), including homosexual-heterosexual friendships (Vonofakou, Hewstone, \& Voci, 2007), to determine how intergroup contact in this context can influence outgroup attitudes. Given the changing nature of family forms over the last few decades (e.g., interracial-ethnic marriages and international adoption), this intergroup perspective is beneficial for understanding families as they are a context often infused with intergroup factors.

Family members are typically thought to share a collective identity that presumes shared meanings and comparable attitudes, values, and beliefs. Obviously, this is a realistic description of family identity in that our family is typically one of the most important social ingroups (Lay et al., 1998). However, in addition to the common ingroup identity of family, family relationships are also influenced by divergent social group identification (e.g., age, religion, political affiliation, ethnicity, and gender) that can create circumstances in which an otherwise personal relationship may shift to a more intergroup relationship. In the latter, perceptions and interaction are based on intergroup factors (i.e., divergent social identities or social categorization) rather than a collective shared family identity (Harwood, Giles, \& Palomares, 2005; Harwood, Soliz, \& Lin, 2006). In this sense, scholars have demonstrated how race and ethnicity (Killian, 2001; Negy \& Snyder, 2000), age group (Harwood, Hewstone, Paolini, \& Voci, 2005; Soliz \& Harwood, 2006), and religion or faith (Hughes \& Dickson, 2005) are social categorizations that influence interaction and functioning in cross-group family relationships. For instance, one's ethnic identity and perceptions of divergent ethnic identities are important aspects of functioning in multiethnic families (Vivero \& Jenkins, 1999; T. K. Williams, 1996). Likewise, stepfamily scholarship has been framed in a common ingroup identity perspective to understand the role of ingroup versus outgroup categorization (i.e., family of origin vs. stepfamily) in creating harmonious relationships (Banker \& Gaertner, 1998; Soliz, 2007).

Because sexual identity is a central social identity for many individuals (Hajek, Abrams, \& Murachver, 2005), relationships between family members with different sexual identities are, by definition, intergroup in nature. Of course, the extent to which intergroup factors influence the relationships is based on the perceptions and 
salience of family versus outgroup categorizations, and, perhaps more important, how families communicatively manage divergent social identities. Based on an intergroup perspective, attitudes toward an outgroup - in this case, homosexuals and homosexuality, in general - can influence perceptions of family members. Hence, these attitudes are an important determinant of relational outcomes. Specifically, more negative attitudes associated with outgroup bias can lead to higher levels of intergroup anxiety (Greenland \& Brown, 2000; Stephan \& Stephan, 1985); this has been shown, as well, in non-family heterosexual-homosexual interactions (Cuenot \& Fugita, 1982). Following this logic, family members with more negative perceptions of homosexuality are more likely to be anxious in communicating with a gay or lesbian family member after learning about his or her sexual identity. Further, as would be expected, higher levels of anxiety are negatively associated with relational satisfaction:

H1: Negative attitudes toward homosexuality prior to learning of the family member's sexual identity are associated with higher levels of intergroup anxiety, which, in turn, are negatively associated with relational satisfaction.

However, intergroup boundaries are managed and negotiated through communication (Harwood, Giles, \& Palomares, 2005) in that our interactions affect and reflect whether we perceive individuals as members of social ingroups or outgroups. Thus, in the family context, communication would be associated with perceptions of the common ingroup of family or with divergent social identities (e.g., ethnicity in multiethnic families, age in grandparent-grandchild relationships, and religion in interfaith families). In this sense, assuming that outgroup attitudes (i.e., perceptions of homosexuality) and the resulting anxiety are the sole predictors of relational satisfaction is misleading. Rather, a more thorough understanding of this family relationship can be attained by investigating communicative aspects associated with relational outcomes. In fact, much of the recent intergroup research on families (Harwood, Hewstone, Paolini, \& Voci, 2005; Harwood, Raman, \& Hewstone, 2006; Soliz \& Harwood, 2006) has examined communicative dimensions associated with a collective family identity, possible outgroup categorizations, and their association with outgroup attitudes. This research is framed in theories of communication accommodation and intergroup contact.

\section{Communication Accommodation Theory}

Communication accommodation theory (CAT; Giles, Coupland, \& Coupland, 1991; Shepard, Giles, \& LePoire, 2001) has been a guiding theoretical perspective for intergroup research, as it demonstrates how communication can both affect and reflect group-based categorization. Specifically, the manner in which individuals attune (or fail to attune) communication to perceived needs and desires of others is associated with the extent to which individuals view the interaction through an intergroup or interpersonal lens. For example, research on grandchildren has shown that non-accommodative behavior on the part of the grandparent (e.g., complaining about health or 
talking down to the grandchild) highlights the age difference-an intergroup distinction - between the family members. Conversely, more accommodative behaviors (e.g., supportive communication, self-disclosure, or storytelling) are more personalized in nature and, thus, the intergroup distinction is not as evident (Harwood, Raman, \& Hewstone, 2006; Soliz \& Harwood, 2006). This intergroup- interpersonal distinction is relevant in that an intergroup perspective of the relationship is typically associated with more negative evaluations (Harwood, Giles, \& Palomares, 2005).

In fact, many of the behaviors discussed in previous research on this context (Merighi \& Grimes, 2000; Morrow, 2004; Oswald, 2002a, 2002b) can be explained through an accommodative perspective. For example, in aiming to create a more affable environment, family members may avoid discussing specific topics associated with sexual identity. However, this type of discourse management (i.e., reluctance to talk about certain topic) is associated with a feeling of constrained communication (Harwood, 2000; A. Williams \& Giles, 1996) and, hence, reflects recognition of the intergroup categorization. Thus, topic avoidance is most likely negatively associated with relational satisfaction. Conversely, openness and self-disclosure may confirm the personal relationship between family members and is positively associated with relational satisfaction (Herek \& Capitanio, 1996; Oswald, 2002a; Soliz \& Harwood, 2006). Likewise, showing respect for others' opinions and perspectives is an accommodative behavior. Whereas this behavior has been conceptualized as it relates to relational roles (Harwood, 2000), demonstrating this respect to others is relevant in this context in which there may be divergent perspectives on sexual identity. Based on accommodative theorizing, we expect more personalized communication - self-disclosure and respectful accommodation - to be negatively associated with topic avoidance. Further, because intergroup anxiety has been shown as a mediator in intergroup contact (Brown \& Hewstone, 2005), it would be valuable to identify any association between family communication and intergroup anxiety. Specifically, we expect that increased perceptions of personalized communication are associated with reduced intergroup anxiety. Based on this theorizing, we pose the following hypotheses:

$\mathrm{H} 2$ : Topic avoidance is negatively associated with self-disclosure and respectful accommodation, whereas self-disclosure and respectful accommodation are positively associated. $\mathrm{H} 3$ : Topic avoidance is a negative predictor of relational satisfaction and a positive predictor of intergroup anxiety.

$\mathrm{H}_{4}$ : Self-disclosure is a positive predictor of relational satisfaction and a negative predictor of intergroup anxiety.

H5: Respectful accommodation is a positive predictor of relational satisfaction and a negative predictor of intergroup anxiety.

Intergroup Contact and the Reduction of Bias

In introducing potential outgroup distinctions in the family, an intergroup perspective also highlights the manner in which communication within the family can 
change perceptions of non-family members. Hence, in this context, can communication with a gay or lesbian family member influence attitudes toward homosexuality?

Since Allport's (1954) early research on intergroup contact, scholars have continued to investigate circumstances that allow for experience in specific situations or relationships to be generalized to the outgroup as a whole (Amir, 1976; Cook, 1978; N. Miller, 2002; Pettigrew, 1997). One of the facilitating conditions for outgroup generalizations is group salience (Brown \& Hewstone, 2005). Specifically, for outgroup generalization to occur, an individual should perceive others as representative (or typical) of their respective social groups and the intergroup distinctions or identities should be salient. Most of the support for this intergroup contact theory comes from experimental designs. However, recent research has explored contact in natural settings (Brown, Vivian, \& Hewstone, 1999). Although this research typically focuses on interaction between strangers or acquaintances, it also demonstrates its utility in family interactions. For example, age salience in grandparent-grandchild interactions facilitates the association between the experiences within the family and perceptions of older adults in general (Harwood, Hewstone, et al., 2005; Soliz \& Harwood, 2006). Hence, in this context and following the tenets of intergroup contact theory, relational satisfaction with a gay or lesbian family member will have a positive effect on attitudes toward homosexuality when a family member's sexual identity is salient:

H6: Relational satisfaction is positively associated with attitudes toward homosexuality when sexual identity of the family member is salient.

Based on these hypotheses, family communication and attitudes toward homosexuality prior to disclosure are associated with present-day attitudes through intergroup anxiety and relational satisfaction mediation. A depiction of the hypothesized relationships is provided in Figure 1.

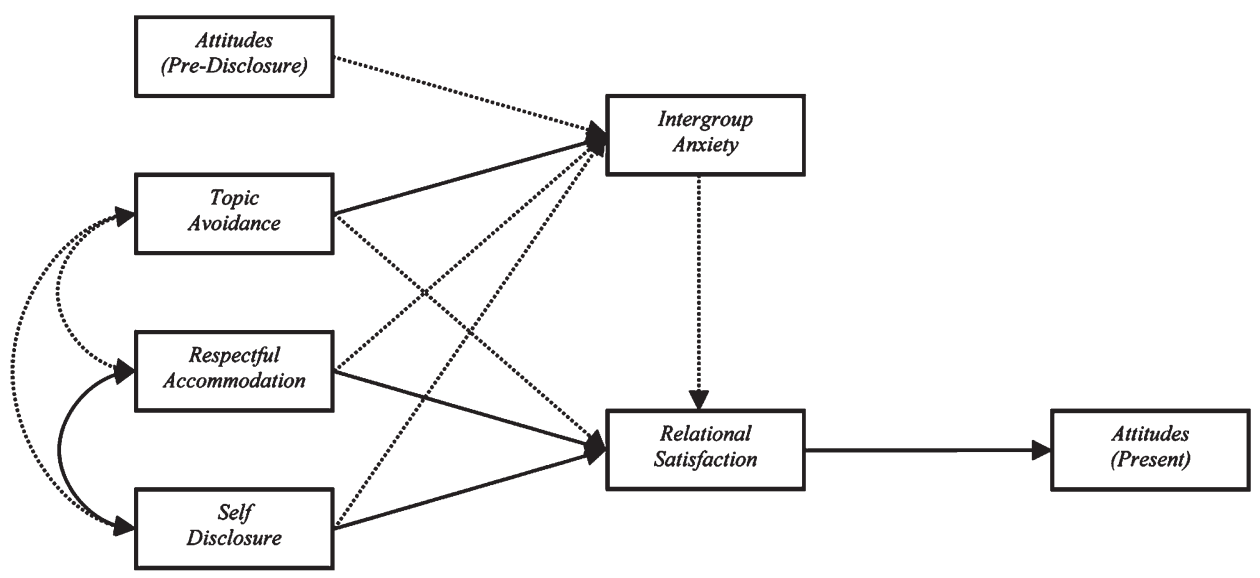

Figure 1. Hypothesized model of family communication and outgroup attitudes. Hypothesized positive relationships are depicted as solid lines, and negative relationships are depicted as dashed lines. 


\section{Method}

Participants

In addition to moving this area of inquiry from a focus on strangers or friendships to the realm of family relationships, we also wanted to capture the experience of nonparent family members (e.g., siblings, children). Data were collected via an online survey. Solicitation for participation was done in two ways. First, e-mail announcements were sent to message boards or electronic mailing lists of organizations for individuals with gay or lesbian family members. These included groups with a more positive orientation toward homosexuality, as well as groups who have a more disapproving orientation toward homosexuality. Second, researchers solicited participation from undergraduate courses. Out of 134 completed questionnaires, a majority of participants (91\%) came through solicitation from the various online groups. Five completed questionnaires were discounted from the analysis because participants answered questions about individuals who are not legally or biologically related. Although we are not discounting the significance of these relationships, this study focused on biological and legal family relationships. Hence, the final data set included 129 participants (76\% women, $24 \%$ men; $18-71$ years old; $M=42.54, S D=17.46$ ). Most identified as White or European American (88.4\%). The remaining participants were Hispanic or Latino (3.9\%), African American (.8\%), Asian American (.8\%), or multiple ethnic identity (6.2\%). Participants reported on a variety of family members: sister $=20.9 \%$, brother $=15.5 \%$, father $=3 \%$, mother $=9.3 \%$, son $=25.6 \%$, daughter $=11.6 \%$, or other family members (e.g., aunt, cousins) $=14 \%$.

\section{Measures}

The questionnaire included a variety of measures, and the following discussion outlines those relevant to this study. Unless noted, all items were measured on a 7-point Likert-type scale. Reliability for each measure is reported for this study.

Attitudes toward homosexuality (pre-disclosure). Participants completed a "feeling thermometer" (Haddock, Zanna, \& Esses, 1993; D. A. Miller, Smith, \& Mackie, 2004), which has been validated to assess general feelings toward a social group. Participants were instructed to indicate their feelings about their family member when they learned of his or her sexual identity rather than their feelings at the present time. Participants were also reminded that this was "not a measure of how you felt toward your family member, but how you felt toward gay men/lesbians and homosexuality, in general." The scale ranged from 0 to 100, with higher numbers indicating more positive perceptions of homosexuals and homosexuality. Although there are limitations with a retrospective account, this measure provides a benchmark important for assessing potential changes in attitudes. 
Intergroup anxiety. Intergroup anxiety was measured with four items developed from previous research on intergroup contact (Harwood, Giles, \& Palomares, 2005; Voci \& Hewstone, 2003). The items assess participants' feelings in conversation with their family members: awkward, happy, self-conscious, and relaxed $(\alpha=.84)$. Higher scores represented higher levels of anxiety.

Accommodative behaviors. Although data come from one family member's perspective, we were interested in assessing behaviors of both family members. Hence, each dimension is a measure of the behavior of the self and others from the participant's perspective. Items for each accommodative behavior were based on previous research (Harwood, 2000; A. Williams \& Giles, 1996; A. Williams et al., 1997), with modifications for this particular study. Topic avoidance was measured with two items: "This family member makes an effort to avoid controversial topics," and "I make an effort to avoid controversial topics" (intraclass correlation $=.73$ ). Respectful accommodation was measured with four items: "This family member is respectful to me and my opinions," and "In our interactions, this family member takes my views and opinions into account" ( $\alpha=$.77). Self-disclosure was measured with two items: "In our conversations, this family member typically shares personal thoughts and feelings," and "In our conversations, I typically share personal thoughts and feelings" (intraclass correlation $=.65)$. For each dimension, higher scores indicate higher levels of the particular behavior in interactions. In line with the tenets of CAT, respectful accommodation $(r=.723, p<.001)$ and self-disclosure $(r=.485, p<.001)$ were positively associated with communication satisfaction, whereas reluctant topic accommodation $(r=-.326$, $p<.001$ ) was negatively related to communication satisfaction. ${ }^{1}$

Relational satisfaction. Relational satisfaction was measured with an adapted version of the Marital Opinion Questionnaire (Huston, McHale, \& Crouter, 1986). Ten semantic differentials are used to assess specific and global dimensions of satisfaction (e.g., miserable-enjoyable and hopeful-discouraging), with higher scores indicating higher satisfaction $(\alpha=.95)$.

Salience of sexual identity. Items were based on previous research on intergroup contact (Brown et al., 1999; Harwood, Hewstone, Paolini, \& Voci, 2005) and included five items that assessed a family member's perception of the salience of sexual identity in interactions with their family member (e.g., "How similar is this family member to other gay men or lesbians?," and "When communicating with this family member, I think a great deal about his/her sexual orientation"; $\alpha=.93$ ). Higher scores represent salience of sexual identity.

Attitudes toward homosexuality (present). Participants completed a slightly modified version of Hansen's (1982) 15-item homosexism scale. Participants were instructed to indicate their current feelings toward homosexuality and again reminded that this was "not a measure of how you feel toward your family member, but how you feel toward gays/lesbians and homosexuality, in general." Higher numbers indicate more positive perceptions of homosexuals and homosexuality $(\alpha=.91)$. 
Topics of conversation. Participants also completed an open-ended question concerning topics of conversation in their interactions.

\section{Results}

Descriptive statistics and intercorrelations are presented in Table 1. A path analysis of the hypothesized model using observed variables was analyzed with AMOS 6.0 (SPSS, Chicago, IL). All exogenous variables were free to covary. This model did not achieve acceptable goodness of fit: $\chi^{2}(6, N=129)=45.794, p<.05 ; \chi^{2} / d f=7.632$; normed fit index $=.828$; comparative fit index $=.838$; root mean square error of approximation $=.228$; and $90 \%$ confidence interval $=0.169-0.291$. However, because this model hypothesized full mediation (via relational satisfaction) of the family communication variables, pre-disclosure attitudes, and intergroup anxiety with post-disclosure attitudes, modifications were made to test for partial mediation. Direct effects of pre-disclosure attitudes, self-disclosure, and intergroup anxiety on post-disclosure attitudes significantly improved model fit: $\Delta \chi^{2}(3, N=129)=41.469, p<.01$. Other direct effects were not significant and did not significantly improve model fit. Finally, removal of two nonsignificant paths (the covariance between respectful accommodation and topic avoidance and the paths between self-disclosure and relational satisfaction) resulted in a more parsimonious model with no significant change in model fit: $\Delta \chi^{2}(2, N=129)=1.957, p>.05$. Results are presented in Figure 2.

Table 1 Descriptive Statistics and Intercorrelations for Relational Dimensions and Outgroup Attitudes

\begin{tabular}{lcccccccc}
\hline Variable & 1 & 2 & 3 & 4 & 5 & 6 & 7 & 8 \\
\hline $\begin{array}{l}\text { 1. Attitudes toward homosexuality } \\
\quad \text { (pre-disclosure) }\end{array}$ & - & & & & & & \\
2. Intergroup anxiety & $-.325^{* *}$ & - & & & & & \\
3. Topic avoidance & -.166 & $.422^{* *}$ & - & & & & \\
4. Respectful accommodation & $.197^{*}$ & $-.499^{* *}$ & -.119 & - & & & & \\
5. Self-disclosure & $.240^{* *}$ & $-.582^{* *}$ & $-.348^{* *}$ & $.504^{* *}$ & - & & & \\
6. Relational satisfaction & .133 & $-.446^{* *}$ & $-.330^{* *}$ & $.411^{* *}$ & $.358^{* *}$ & - & & \\
7. Salience of sexual identity & .025 & -.172 & .106 & $.216^{*}$ & .091 & .083 & - & \\
8. Attitudes toward & $.390^{* *}$ & $-.542^{* *}$ & $-.399^{* *}$ & $.391^{* *}$ & $.480^{* *}$ & $.460^{* *}$ & .062 & - \\
$\quad$ homosexuality (present) & & & & & & & & \\
$M$ & 64.93 & 1.82 & 2.87 & 6.42 & 6.10 & 6.14 & 4.48 & 6.57 \\
SD & 24.03 & 1.07 & 1.64 & 0.76 & 1.06 & 1.23 & 1.18 & 0.71 \\
\hline
\end{tabular}

${ }^{*} p<.05 ;{ }^{* *} p<.01$ 


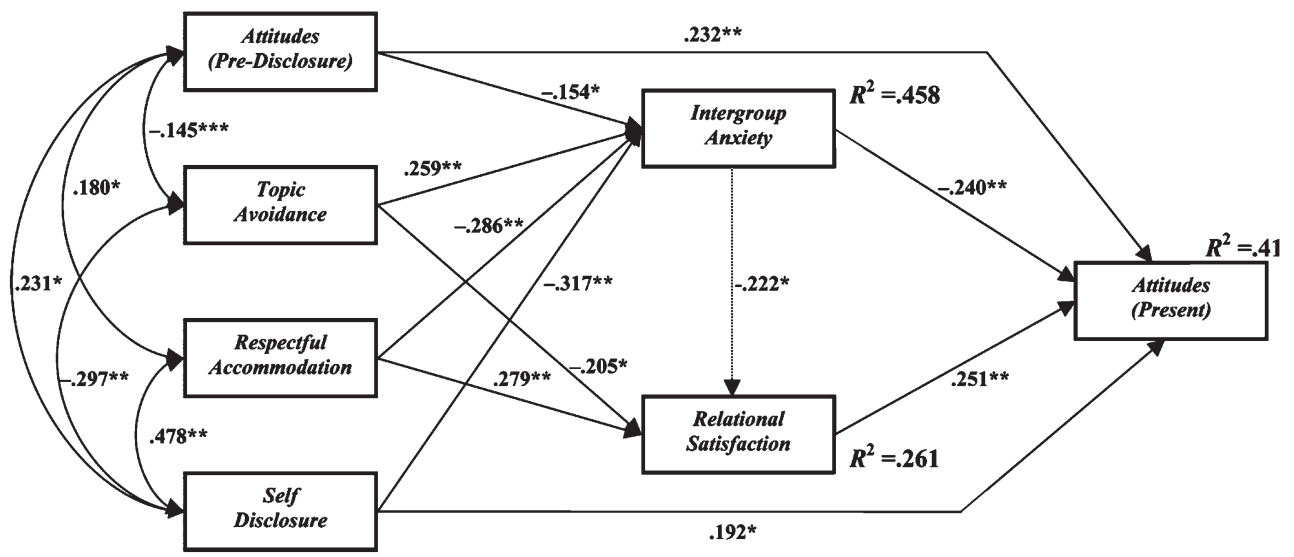

Figure 2. Path Analysis of Family Communication and Outgroup Attitudes. $\chi^{2}(5, N=129)=6.257$, $p=.282 ; \chi^{2} / d f=1.251$; Normed Fit Index $=.977$; Comparative Fit Index $=.995$; Root Mean Square Error of Approximation $=.044(90 \%$ Confidence Interval $=.000-.137) .{ }^{*} p<.05 ;{ }^{* *} p<.01 ;{ }^{* *} p<.10$

Based on the path analysis, intergroup anxiety mediates the relationship between negative attitudes prior to learning of a family member's sexual identity and relational satisfaction, supporting H1. H2 was partially supported in that topic avoidance was negatively associated with self-disclosure, but not respectful accommodation. However, self-disclosure and respectful accommodation were positively associated. Supporting H3, topic avoidance was negatively associated with relational satisfaction and positively associated with intergroup anxiety indicating direct and indirect (via intergroup anxiety) effects on relational satisfaction. Thematic analysis of openended responses concerning topics in conversations suggests that discussions of relationships, politics and, to a lesser extent, sex and religion are the most commonly avoided topics from the participant's perspective. $H 4$ was partially supported in that self-disclosure was negatively associated with intergroup anxiety, but was not a significant predictor of relational satisfaction. However, self-disclosure has a mediated route to relational satisfaction via intergroup anxiety. Likewise, selfdisclosure was shown to be directly associated with present attitudes. Respectful accommodation was positively associated with relational satisfaction and negatively associated with intergroup anxiety, supporting H5. Although not hypothesized, pre-disclosure attitudes were negatively associated with topic avoidance (with marginal significance) and positively associated with self-disclosure and respectful accommodation.

To test H6, we examined the interaction effect for relational satisfaction and salience in predicting post-disclosure attitudes through a regression model. The interaction was not a significant predictor of post-disclosure attitudes, demonstrating that salience of sexual identity did not significantly moderate the relationship between relational satisfaction and these attitudes: $\beta=-.052 ; p=.16$. Hence, H6 was not supported. However, based on the path analysis, there was a main effect for relational satisfaction on post-disclosure attitudes. 


\section{Discussion}

Guided by the theories of intergroup contact, we investigated perceptions of communication in families with gay or lesbian members to determine communicative and cognitive predictors of relational satisfaction and intergroup anxiety, as well as the manner in which family interactions may be related to attitudes toward homosexuality, in general. The findings have implications for theorizing on family communication and intergroup contact. Most of the research on interactions between individuals with different sexual identities has focused on strangers or mere acquaintances with some minimal research on personal relationships. The research that has investigated families has focused on many of the negative aspects of disclosure and parental reaction. Obviously, sexual identity can create challenges for these families. However, as this study demonstrates, it is important to look at the family communication dynamics to understand how the attitudes are manifested in communication and, more important, how communication can transcend any differences or difficulties associated with divergent sexual identities. CAT presents a lens to understand this.

As expected, topic avoidance was associated with intergroup anxiety and negatively associated with relational satisfaction. We might expect topic avoidance to be associated with a more pleasant relationship as individuals strategically create an interactive context in which everyone is comfortable. However, in recognizing that communication with a family member is constrained, one may feel that his or her relationship with the family member is less fulfilling and, thus, less satisfying. Likewise, if family members are constantly monitoring their discourse in conversations, the resulting anxiety is not surprising. Hence, although it may be a worthy goal for family members to try to make specific conversations comfortable, the negative association with relational satisfaction suggests that addressing these topics head-on may be better for the relationship.

Topic avoidance is likely influenced by recognition of sexual identity and, hence, group distinction. Conversely, respectful accommodation and self-disclosure reflect more person-centered communication. In this, both are negatively associated with anxiety in interactions and thus may have positive consequences for the relationship either through direct effects on relational satisfaction or through the mediated path of intergroup anxiety. The fact the self-disclosure was not directly associated with relational satisfaction warrants further investigation as its role in this process may depend on topics of disclosure or individual expectations of disclosure. For example, disclosing about the first semester at college may be viewed more positively than disclosure about romantic relationships. Finally, the results showed that pre-disclosure attitudes concerning homosexuality were associated with family communication behaviors. This finding coupled with the fact that many of the topics that were purposely circumvented in interactions dealt with issues commonly associated with the public discourse on sexual identity (e.g., relationships, politics, and religion) further supports the idea that the family context is not immune to the perceptual and behavioral consequences of group categorization present in society. Likewise, in evaluating these communication dimensions, this work builds off research (Harwood, 
Hewstone, et al., 2005; Soliz, 2007; Soliz \& Harwood, 2006) that takes a more nuanced perspective on intergroup contact by focusing on specific behaviors rather than general assessments of quality of contact.

Building on this study, we envision multiple directions for future inquiry on family communication dynamics in these relationships. First, because this study focused on one family member, an emphasis on a systems level perspective of the family would be beneficial to determine the interdependence of attitudes and communication among family members. For example, does a mother's interaction with her gay son influence siblings' communication with their brother and their attitudes toward homosexuality, in general? Likewise, assessing perceptions of multiple family members would provide a more thorough assessment of family functioning. Second, in accounting for $26 \%$ of the variance in relational satisfaction, there are clearly other predictors of relational satisfaction that should be teased out. These may be communicative (e.g., process of disclosing sexual identity) and relational (e.g., closeness and type of family relationship) in nature or may include cognitive factors (e.g., motivation, personality, or religious and moral beliefs).

Third, because researchers (Herek, 1991, 2000; Kite \& Whitley, 1996; LaMar \& Kite, 1998) suggest that there are gender differences for both perceivers (i.e., male or female) and the target (i.e., gay man or lesbian), future studies should aim to attain samples in which family processes can be compared across various dyads (e.g., heterosexual male-homosexual male, heterosexual male-homosexual female) to test for potential gender interactions. Finally, with the growing number of same-sex marriages and civil unions and the corresponding social debate, scholars should focus on similarities and differences in family communication practices associated with incorporating heterosexual and homosexual partners into the family. Hence, extending this line of research to gain a more comprehensive understanding of the dynamics of these families could be the first step in improving what can often be a strenuous and uncomfortable point in the lives of all individuals involved.

In addition to understanding communicative dynamics of the family, an intergroup perspective sensitizes us to important features of family relationships. Specifically, the fact that intergroup distinctions are present (i.e., divergent sexual identities) suggests that intergroup anxiety can exist in what is typically considered an ingroup (i.e., family) orientation. Not only is intergroup anxiety present, but the results demonstrate that it is associated with communication and outgroup attitudes. This is significant for intergroup research in that it further supports the role of intergroup anxiety in intergroup contact (Greenland \& Brown, 2000). Moreover, these findings demonstrate that intergroup anxiety may be influenced by factors other than outgroup attitudes or categorization. In this case, self-disclosure, topic avoidance, and respectful accommodation were all significantly associated with intergroup anxiety.

Based on intergroup contact theory (Brown \& Hewstone, 2005), we hypothesized that interactions with a gay or lesbian family member and the resulting relational satisfaction may be generalized to attitudes toward homosexuality when sexual identity is salient. In general, this hypothesis was not supported. Although relational satis- 
faction was positively associated with outgroup attitudes, these findings did not support the theorizing that this association was dependent on the moderating effect of group salience. Further, results showed direct effects of pre-disclosure attitudes, intergroup anxiety, and self-disclosure on present outgroup attitudes.

It is not surprising that the pre-disclosure attitudes would be associated with present attitudes considering that it is unlikely that contact would generate such a dramatic shift in perceptions that initial attitudes are inconsequential. Moreover, this finding may be convoluted by the retrospective nature of the measure. Although we expected a mediated effect of intergroup anxiety on outgroup attitudes, these results support previous studies (Islam \& Hewstone, 1993; Paolini et al., 2004), which suggest that anxiety associated with intergroup contact, even in personal relationships, has negative consequences for perceptions. Finally, whereas self-disclosure in intergroup contact has been shown to reduce anxiety, enhance relational depth, engender trust, and the like (for a review, see Brown \& Hewstone, 2005), this study suggests this behavior may be directly linked to outgroup attitudes.

In terms of the lack of support for the group salience hypothesis, we put forth two possible explanations. First, as stipulated in Brewer and Miller's decategorization model (as cited in N. Miller, 2002), a more interpersonal orientation (i.e., not viewing the individual in terms of group membership) is an important condition for improved outgroup attitudes. In others words, as individuals perceive others on an individualized level, there is more differentiation in their perceptions of outgroups. This, in turn, negates the effects of negative stereotypes as individuals realize variation in outgroup members.

Both Brewer and Miller's decategorization perspective (as cited in N. Miller, 2002) and Brown and Hewstone's (2005) group salience hypothesis have received empirical support from mostly experimental designs using artificial groups. However, correlational designs investigating naturally occurring intergroup contact have become more common. As with this study, this latter approach is typically a cross-sectional perspective and, thus, results should be interpreted with the limitations of crosssectional designs in mind. Hence, longitudinal designs may shed light on the specific process by which family communication can influence outgroup attitudes. In fact, the study was limited in that the pre-existing measure was retrospective in nature. $\mathrm{Ob}-$ viously, a retrospective account can be biased by present attitudes or circumstances. Although pre-disclosure attitudes were far less positive than post-disclosure attitudes, and there was only a low to moderate relationship between pre- and post-disclosure attitudes, a longitudinal study would allow for a more valid assessment of attitude change across time. In addition, the intergroup contact literature continues to introduce various factors (e.g., motivation) that may explain the cognitive process of outgroup generalization. Heterosexual-homosexual interactions (within and outside of the family) are a context where this research is applicable and necessary considering the current social climate of heterosexual-homosexual attitudes.

A second possible explanation for the lack of support of H5 is that outgroup attitudes are influenced by vicarious contact. For example, a vast majority of our par- 
ticipants were solicited from small groups in which all participants had a gay or lesbian family member. Perhaps discussing or hearing about other family experiences can influence attitudes. In addition, contact through media may have an effect on attitudes. In other words, whereas direct contact may have implications for outgroup attitudes, we should also consider how this intersects with vicarious and mediated contact overall.

In addition to the aforementioned directions for future research, there are additional limitations of this study that offer avenues for additional inquiry. First, the relationships depicted in this model should be validated on additional samples especially those with more ethnic and racial diversity and more equal representation in gender of participants. Further, this study assessed perceptions of communication, which may not reflect the actual communication occurring in these interactions. Likewise, attitudes were assessed with explicit measures in which responses can be influenced by social desirability bias. Hence, future studies should account for this subjectivity bias of participants by examining actual family interactions and assessing attitudes through methods that account for social desirability. In light of the limitations of this study, we believe it offers a unique perspective for understanding family functioning and intergroup contact. As new family structures and forms continue to emerge, an intergroup perspective provides a lens to understand the family dynamics. For example, interracial-ethnic and interfaith family members must communicatively manage a common family identity, as well as distinct social identities. Further, family interactions with both immediate and extended family members may have positive or negative consequences for attitudes toward various social groups. Hence, family scholars should consider the theories and models of intergroup contact (e.g., Intergroup Contact Theory and (AT) as they continue to expand our knowledge of family functioning and the importance of families in influencing our attitudes toward others.

\section{Note}

1. Communication satisfaction was measured with a condensed version of Hecht's (1978) Communication Satisfaction scale $(\alpha=.77 ; M=6.22, S D=0.83)$.

\section{References}

Allport, G. W. (1954). The nature of prejudice. Reading, MA: Addison-Wesley.

Amir, Y. (1976). The role of intergroup contact in change of prejudice and race relations. In P. A. Katz (ed.), Towards the elimination of racism (pp. 245-280). New York: Pergamon.

Banker, B. S., \& Gaertner, S. L. (1998). Achieving stepfamily harmony: An intergroup-relations approach. Journal of Family Psychology, 12, 310-325.

Ben-Ari, A. (1995). The discovery that an offspring is gay: Parents', gay men's, and lesbians' perspectives. Journal of Homosexuality, 30, 89-112.

Bergen, K. M., Suter, E. A., \& Daas, K. L. (2006). “About as solid as a fishnet": Symbolic construction of a legitimate parental identity for nonbiological lesbian mothers. Journal of Family Communication, 6, 201-220. 
Boxer, A. M., Cook, J. A., \& Herdt, G. (1991). Double jeopardy: Identity transitions and parent-child relations among gay and lesbian youth. In K. Pillemer \& K. McCartney (eds.), Parent-child relations throughout life (pp. 59-91). Hillsdale, NJ: Lawrence Erlbaum Associates, Inc.

Brown, R., \& Hewstone, M. (2005). An integrative theory of intergroup contact. Advances in Experimental Social Psychology, 37, 255-343.

Brown, R., Vivian, J., \& Hewstone, M. (1999). Changing attitudes through intergroup contact: The effects of group membership salience. European Journal of Social Psychology, 29, 741-764.

Cook, S. W. (1978). Interpersonal and attitudinal outcomes in cooperating interracial groups. Journal of Research and Development in Education, 12, 97-113.

Cuenot, R. G., \& Fugita, S. S. (1982). Perceived homosexuality: Measuring heterosexual attitudinal and nonverbal reactions. Personality and Social Psychology Bulletin, 8, 100-106.

D’ Augelli, R. R., Hershberger, S. L., \& Pilkington, N. W. (1998). Lesbian, gay, and bisexual youth and their families: Disclosure of sexual orientation and its consequences. American Journal of Orthopsychiatry, 68, 361-371.

Day, N. E., \& Schoenrade, P. (1997). Staying in the closet versus coming out: Relationships between communication about sexual orientation and work attitudes. Personal Psychology, 50, 147-163.

Diggs, R. C., \& Clark, K. D. (2002). It's a struggle but worth it: Identifying and managing identities in an interracial friendship. Communication Quarterly, 50, 368-390.

Floyd, K. (2001). Human affection exchange: Reproductive probability as a predictor of men's affection with their sons. Journal of Men's Studies, 10, 39-50.

Gaines, S. O., Jr., Granrose, C. S., Rios, D. I., Garcia, B. F., Youn, M. S., Farris, K. R., et al. (1999). Patterns of attachment and response to accommodative dilemmas among interethnic/interracial couples. Journal of Social and Personal Relationships, 16, 275-284.

Galvin, K. M. (2006). Diversity's impact on defining the family: Discourse-dependence and identity. In L. H. Turner \& R. West (eds.), The family communication sourcebook (pp. 3-20). Thousand Oaks, CA: Sage.

Giles, H., Coupland, N., \& Coupland, J. (1991). Accommodation theory: Communication, context, and consequence. In H. Giles, J. Coupland, \& N. Coupland (eds.), Contexts of accommodation: Developments in applied sociolinguistics (pp. 1-68). Cambridge, England: Cambridge University Press.

Greenland, K., \& Brown, R. (2000). Categorization and intergroup anxiety in intergroup contact. In D. Capozza \& R. Brown (eds.), Social identity processes (pp. 167-183). London: Sage.

Haddock, G., Zanna, M. P., \& Esses, V. M. (1993). Assessing the structure of prejudicial attitudes: The case of attitudes toward homosexuals. Journal of Personality and Social Psychology, 65, 1105-1118.

Hajek, C., Abrams, J. R., \& Murachver, T. (2005). Female, straight, male, gay and worlds betwixt and between: An intergroup approach to sexual and gender identities. In J. Harwood \& H. Giles (eds.), Intergroup communication: Multiple perspectives (pp. 43-64). New York: Peter Lang.

Hansen, G. L. (1982). Measuring prejudice against homosexuals (homosexism) among college students: A new scale. Journal of Social Psychology, 117, 233-236.

Harwood, J. (2000). Communicative predictors of solidarity in the grandparent-grandchild relationship. Journal of Social and Personal Relationships, 17, 743-766.

Harwood, J. (2006). Social identity. In G. Shepherd, J. St. John, \& T. Striphas (eds.), Communication as ... . Perspectives on theory (pp. 84-90). Thousand Oaks, CA: Sage.

Harwood, J., \& Giles, H. (eds.) (2005). Intergroup communication: Multiple perspectives. New York: Peter Lang. 
Harwood, J., Giles, H., \& Palomares, N. A. (2005). Intergroup theory and communication processes. In J. Harwood \& H. Giles (eds.), Intergroup communication: Multiple perspectives (pp. 1-20). New York: Peter Lang.

Harwood, J., Hewstone, M., Paolini, S., \& Voci, A. (2005). Grandparent-grandchild contact and attitudes towards older adults: Moderator and mediator effects. Personality and Social Psychology Bulletin, 31, 393-406.

Harwood, J., Raman, P., \& Hewstone, M. (2006). The family and communication dynamics of group salience. Journal of Family Communication, 6, 181-200.

Harwood, J., Soliz, J., \& Lin, M.-C. (2006). Communication accommodation theory: An intergroup approach to family relationships. In D. O. Braithwaite \& L. Baxter (eds.), Engaging theories in family communication: Multiple perspectives (pp. 19-34). Thousand Oaks, CA: Sage.

Hecht, M. L. (1978). The conceptualization and measurement of interpersonal communication satisfaction. Human Communication Research, 4, 253-264.

Herek, G. M. (1991). Stigma, prejudice, and violence against gay men and lesbians. In J. C. Gonsiorek \& J. D. Weinrich (eds.), Homosexuality: Research implications for public policy (pp. 60-80). Newbury Park, CA: Sage.

Herek, G. M. (1994). Assessing heterosexuals' attitudes toward lesbians and gay men: A review of empirical research with the ATLG scale. In B. Greene \& G. M. Herek (eds.), Lesbian and gay psychology: Theory, research, and clinical applications (pp. 206-228). Thousand Oaks, CA: Sage.

Herek, G. M. (2000). Sexual prejudice and gender: Do heterosexuals' attitudes toward lesbians and gay men differ? Journal of Social Issues, 56, 251-266.

Herek, G. M., \& Capitanio, J. P. (1996). "Some of my best friends": Intergroup contact, concealable stigma, and heterosexuals" attitudes toward gay men and lesbians. Personality and Social Psychology Bulletin, 22, 412-424.

Hughes, P. C., \& Dickson, F. C. (2005). Communication, marital satisfaction, and religious orientation in interfaith marriages. Journal of Family Communication, 5, 25-41.

Huston, T. L., McHale, S. M., \& Crouter, A. C. (1986). When the honeymoon's over: Changes in the marriage relationship over the first year. In R. Gilmour \& S. W. Duck (eds.), The emerging field of personal relationships (pp. 109-132). Hillsdale, NJ: Lawrence Erlbaum Associates, Inc.

Islam, M. R., \& Hewstone, M. (1993). Dimensions of contact as predictors of intergroup anxiety, perceived out-group variability, and out-group attitudes: An integrative model. Personality and Social Psychology Bulletin, 19, 700-710.

Killian, K. D. (2001). Reconstituting racial histories and identities: The narratives of interracial couples. Journal of Marital and Family Therapy, 27, 27-42.

Kite, M. E., \& Whitley, B. E., Jr. (1996). Sex differences in attitudes toward homosexual persons, behavior, and civil rights: A meta-analysis. Personality and Social Psychology Bulletin, 22, 336-353.

Kourany, R. F. (1987). Suicide among homosexual adolescents. Journal of Homosexuality, 13, 111-117.

LaMar, L., \& Kite, M. (1998). Sex differences in attitudes toward gay men and lesbians: A multidimensional perspective. Journal of Sex Research, 35, 189-196.

LaSala, M. C. (2000). Lesbians, gay men, and their parents: Family therapy for the coming-out crisis. Family Process, 39, 67-81.

Lay, C., Fairlie, P., Jackson, S., Ricci, T., Eisenberg, J., Sato, T., et al. (1998). Domain-specific allocentrism-idiocentrism: A measure of family connectedness. Journal of Cross-Cultural Psychology, 29, 434-460.

Mays, V. M., Chatters, L. M., Cochran, S. D., \& Mackness, J. (1998). African American families in diversity: Gay men and lesbians as participants in family networks. Journal of Comparative Family Studies, 29, 73-87. 
Merighi, J. R., \& Grimes, M. D. (2000). Coming out to families in a multicultural context. Families in Society, 81, 32-41.

Miller, D. A., Smith, E. R., \& Mackie, D. M. (2004). Effects of intergroup contact and political predispositions on prejudice: Role of intergroup emotions. Group Processes E Intergroup Relations, 7, 221-237.

Miller, N. (2002). Personalization and the promise of contact theory. Journal of Social Issues, 58, 387-410.

Morrow, D. F. (2004). Social work practice with gay, lesbian, bisexual, and transgender adolescents. Families in Society, 85, 91-99.

Mosher, C. M. (2001). The social implications of sexual identity formation and the coming-out process: A review of the theoretical and empirical literature. The Family Journal, 9, 164-173.

Negy, C., \& Snyder, D. K. (2000). Relationship satisfaction of Mexican-American and non-Hispanic White interethnic couples: Issues of acculturation and clinical intervention. Journal of Marital and Family Therapy, 26, 293-304.

Oswald, R. F. (2002a). Resilience within the family networks of lesbians and gay men: Intentionality and redefinition. Journal of Marriage and Family, 64, 374-383.

Oswald, R. F. (2002b). Who am I in relation to them? Gay, lesbian, and queer people leave the city to attend rural family weddings. Journal of Family Issues, 23, 323-348.

Paolini, S., Hewstone, M., Cairns, E., \& Voci, A. (2004). Effects of direct and indirect cross-group friendships on judgments of Catholics and Protestants in Northern Ireland: The mediating role of an anxiety-reduction mechanism. Personality and Social Psychology Bulletin, 30, 770-786.

Peplau, L. A., \& Beals, K. P. (2004). The family lives of lesbians and gay men. In A. Vangelisti (ed.), Handbook of family communication (pp. 233-248). Mahwah, NJ: Lawrence Erlbaum Associates, Inc.

Pettigrew, T. F. (1997). Generalized intergroup contact effects on prejudice. Personality and Social Psychology Bulletin, 23, 173-185.

Robbins, M., Szapocznik, J., Tejeda, M., Samuels, D., Ironson, G., \& Antoni, M. (2003). The protective role of the family and social support network in a sample of HIV-positive African American women: Results of a pilot study. Journal of Black Psychology, 29, 17-37.

Saltzburg, S. (2004). Learning that an adolescent child is gay or lesbian: The parent experience. Social Work, 49, 109-118.

Seidman, S., Meeks, C., \& Traschen, F. (1999). Beyond the closet? The changing social meaning of homosexuality in the United States. Sexualities, 2, 9-34.

Shepard, C. A., Giles, H., \& LePoire, B. A. (2001). Communication accommodation theory. In W. P. Robinson \& H. Giles (eds.), The new handbook of language and social psychology (pp. 33-56). Chichester, England: Wiley.

Soliz, J. (2007). Communicative predictors of a shared family identity: Comparison of grandchildren's perceptions of family-of-origin grandparents and stepgrandparents. Journal of Family Communication, 7, 177-194.

Soliz, J., \& Harwood, J. (2006). Shared family identity, age salience, and intergroup contact: Investigation of the grandparent-grandchild relationship. Communication Monographs, 73, 87-107.

Stephan, W. G., \& Stephan, C. W. (1985). Intergroup anxiety. Journal of Social Issues, 41, 157-175.

Suter, E. A., Daas, K. L., \& Bergen, K. M. (2008). Negotiating lesbian family identity via symbols and rituals. Journal of Family Issues, 29, 26-47.

Troy, A. B., Lewis-Smith, J., \& Laurenceau, J.-P. (2006). Interracial and intraracial romantic relationships: The search for differences in satisfaction, conflict, and attachment style. Journal of Social and Personal Relationships, 23, 65-80. 
Turner, L. H., \& West, R. (2003). Breaking through silence: Increasing voice for diverse families in communication research. Journal of Family Communication, 3, 181-186.

Vivero, V. N., \& Jenkins, S. R. (1999). Existential hazards of the multicultural individual: Defining and understanding "cultural homelessness." Cultural Diversity and Ethnic Minority Psychology, 5, 6-26.

Voci, A., \& Hewstone, M. (2003). Intergroup contact and prejudice toward immigrants in Italy: The mediational role of anxiety and the moderational role of group salience. Group Processes $\mathcal{E}$ Intergroup Relations, 6, 37-54.

Vonofakou, C., Hewstone, M., \& Voci, A. (2007). Contact with out-group friends as a predictor of meta-attitudinal strength and accessibility of attitudes toward gay men. Journal of Personality and Social Psychology, 92, 804-820.

West, R., \& Turner, L. H. (1995). Communication in gay and lesbian families: Building a descriptive base. In T. J. Socha \& G. H. Stamp (eds.), Parents, children, and communication: Frontiers of theory and research (pp. 147-169). Mahwah, NJ: Lawrence Erlbaum Associates, Inc.

Williams, A., \& Giles, H. (1996). Intergeneration conversations: Young adults' retrospective accounts. Human Communication Research, 23, 220-250.

Williams, A., Ota, H., Giles, H., Pierson, H., Gallois, C., Ng, S.-H., et al. (1997). Young people's beliefs about intergenerational communication: An initial cross-cultural analysis. Communication Research, 24, 370-393.

Williams, T. K. (1996). Race as process: Reassessing the "What are you?" encounters of biracial individuals. In M. P. Root (ed.), The multiracial experience: Racial borders as the new frontier (pp. 191209). Thousand Oaks, CA: Sage. 